\title{
Effect of Hydration on Porous Anodic Alumina with Large Interpore Distances during Anodization with Ultrahigh Voltage
}

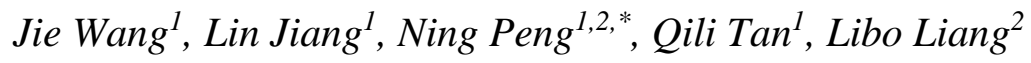 \\ ${ }^{1}$ Guangxi Key Laboratory of Electrochemical and Magnetochemical Functional Materials, Guilin \\ University of Technology, 541004, Guilin, China \\ ${ }^{2}$ Institute of Technology Research and Development of Electronic Aluminum Foil, Guangxi Hezhou \\ Guidong Electronics Technology Co. Ltd., 542800 Guangxi, China \\ *E-mail: ncdxclpn@163.com (N. Peng).
}

doi: $10.20964 / 2021.03 .04$

Received: 2 November 2020 / Accepted: 17 December 2020 / Published: 31 January 2021

\begin{abstract}
The effects of the hydrated alumina film obtained from hydration process on the porous anodic alumina (PAA) film fabricated under the ultrahigh voltage in a mixed electrolyte were investigated. It is found that the hydrated alumina film can enhance the voltage of anodization and facilitate the uniform growth of the PAA film. The suitable thickness of the hydrated alumina film can be used to facilitate the selfassembly formation of the unite cell on porous PAA film. Besides, it is found that some of aluminum nanocones is presented on the sidewalls of the nanodents, due to the relatively poor self-assembly of the nano-structural units, which result in the inadequacy transformation of the aluminum between the nanostructural units to the alumina. These finding may can be used for fabricating the aluminum nanostructure on the aluminum surface directly.
\end{abstract}

Keywords: Porous film; Hydration; ultrahigh voltage; nanocones; Phosphoric acid;

\section{$\underline{\text { FULL TEXT }}$}

(C) 2021 The Authors. Published by ESG (www.electrochemsci.org). This article is an open access article distributed under the terms and conditions of the Creative Commons Attribution license (http://creativecommons.org/licenses/by/4.0/). 